\title{
SOEP
}

SOEPpapers

SOEPDaNoers
on Multidisciplinary Panel Data Research

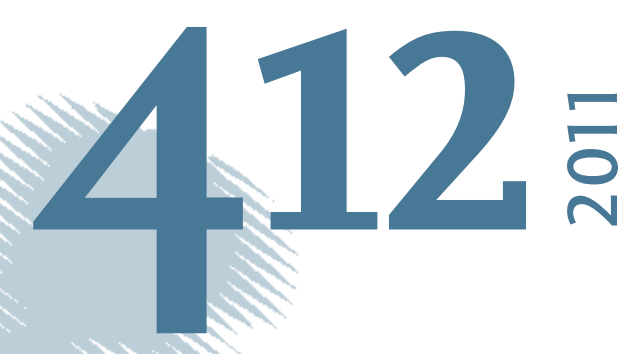

\section{Intergenerational Transmission of Risk Attitudes - A Revealed Preference Approach}




\section{SOEPpapers on Multidisciplinary Panel Data Research}

at DIW Berlin

This series presents research findings based either directly on data from the German SocioEconomic Panel Study (SOEP) or using SOEP data as part of an internationally comparable data set (e.g. CNEF, ECHP, LIS, LWS, CHER/PACO). SOEP is a truly multidisciplinary household panel study covering a wide range of social and behavioral sciences: economics, sociology, psychology, survey methodology, econometrics and applied statistics, educational science, political science, public health, behavioral genetics, demography, geography, and sport science.

The decision to publish a submission in SOEPpapers is made by a board of editors chosen by the DIW Berlin to represent the wide range of disciplines covered by SOEP. There is no external referee process and papers are either accepted or rejected without revision. Papers appear in this series as works in progress and may also appear elsewhere. They often represent preliminary studies and are circulated to encourage discussion. Citation of such a paper should account for its provisional character. A revised version may be requested from the author directly.

Any opinions expressed in this series are those of the author(s) and not those of DIW Berlin. Research disseminated by DIW Berlin may include views on public policy issues, but the institute itself takes no institutional policy positions.

The SOEPpapers are available at

http://www.diw.de/soeppapers

\section{Editors:}

Joachim R. Frick (Empirical Economics)

Jürgen Schupp (Sociology, Vice Dean DIW Graduate Center)

Gert G. Wagner (Social Sciences)

Conchita D'Ambrosio (Public Economics)

Denis Gerstorf (Psychology, DIW Research Professor)

Elke Holst (Gender Studies)

Frauke Kreuter (Survey Methodology, DIW Research Professor)

Martin Kroh (Political Science and Survey Methodology)

Frieder R. Lang (Psychology, DIW Research Professor)

Henning Lohmann (Sociology, DIW Research Professor)

Jörg-Peter Schräpler (Survey Methodology, DIW Research Professor)

Thomas Siedler (Empirical Economics, DIW Graduate Center)

C. Katharina Spieß (Empirical Economics and Educational Science)

ISSN: 1864-6689 (online)

German Socio-Economic Panel Study (SOEP)

DIW Berlin

Mohrenstrasse 58

10117 Berlin, Germany

Contact: Uta Rahmann | soeppapers@diw.de 


\title{
Intergenerational Transmission of Risk Attitudes - A Revealed Preference Approach*
}

\author{
Andrea Leuermann ${ }^{\dagger} \quad$ Sarah Necker ${ }^{\ddagger}$
}

November 7, 2011

\begin{abstract}
This study investigates whether the willingness to take income risks revealed by occupational choice is transmitted from parents to their children. Using data from the German Socio-Economic Panel (SOEP), we find that fathers' riskiness of job is a significant determinant of children's occupational risk, in particular sons' (excluding parent-child pairs with identical occupations). This is the first piece of evidence for intergenerational transmission of risk attitudes relying on real world behavior. It shows that not only individuals' own assessments of their risk attitudes correlate across generations (found by previous studies) but also risk preferences shown in exactly the same situation.
\end{abstract}

Classification: Risk preferences, intergenerational transmission, occupational choice

JEL Code: D12, D81, J24

*We thank Melanie Arntz, Holger Bonin, Armin Falk, Andreas Roider, Uwe Sunde, Johannes Diederich and Johannes Jarke for helpful suggestions and discussions. We benefited from comments of participants of the Regional Workshop of Public Economics in Mannheim 2009, seminars in Heidelberg and St. Gallen in 2010, at the Thurgau Experimental Economics Meeting in Konstanz 2010, the Economic Science Association World Meeting in Copenhagen 2010, the 2010 Congress of the European Economic Association in Glasgow and the Annual Meeting of the Verein für Socialpolitik in Kiel 2010.

†andrea.leuermann@awi.uni-heidelberg.de, University of Heidelberg, Bergheimer Str. 58, 69115 Heidelberg, Germany

${ }^{\ddagger}$ sarah.necker@vwl.uni-freiburg.de, University of Freiburg, Platz der Alten Synagoge, 79085 Freiburg 
A crucial determinant of almost any decision in life is an individual's risk attitude. The often observed similarity between children's and parents' income or wealth suggests resemblance of their decisions. Given its importance, an underlying reason might be similarity of their risk taking. While several studies find that parents and children report similar risk attitudes in surveys, no evidence exists showing that parents and children also exhibit the same willingness to take risk in real life situations. The lively debate regarding the appropriate measurement of risk attitudes strongly suggests that it is important to study whether intergenerational transmission of risk attitudes can also be established in a revealed preference approach.

Previous evidence for intergenerational transmission is based on selfassessments of individuals' risk attitudes (Charles and Hurst (2003), Arrondel (2009), Hryshko et al. (2011) and Dohmen et al. (forthcoming)). While all studies find a significantly positive correlation between children's and parents' risk tolerance, in some of the analyses the link depends on the respondent's strength of risk aversion. A few tentative attempts have been made to explain children's stated risk attitudes with the parents' actual risk behavior, i.e., them being self-employed (De Paola forthcoming, Hryshko et al. 2011). However, thorough evidence for children and parents showing similarly risky behavior is lacking.

The advantage of survey data is that they offer an easy way to learn about individual's attitudes. The validity of responses to survey questions, however, suffers from a number of biases (e.g. Bertrand and Mullainathan 2001). Dohmen et al. (2011) mitigate concerns by validating the reliability of the stated risk preferences employed by Dohmen et al. (forthcoming) in an experiment. However, analyses dealing with the consistency of an individual's risk attitude across measures experimentally elicited and those based on surveys yield contradictory results (e.g. Deck et al. 2008, Anderson and Mellor 2009). While stated risk preferences have been found to be a significant determinant of actual risk taking behavior, they only explain a small fraction of the variation in real world decisions (Barsky et al. 1997).

An explanation for these results is that risk preferences differ across contexts (Weber et al. 2002, Dohmen et al. 2011). Such differences are hardly 
captured by lottery questions or individuals' global assessments of their risk attitude on which most stated preference approaches are based. Dohmen et al. (forthcoming) provide evidence for intergenerational transmission based on self-reported risk attitudes regarding different domains, e.g. health and career. Yet the question whether parents and children also exhibit similar risk behavior in exactly the same situation remains open.

The purpose of the present paper is to study these issues. Employing a revealed preference approach, we endorse the method traditionally pursued by economists. We focus on the willingness to take risk revealed by an individual's actual job choice. According to the theory of compensating wage differentials, individuals are compensated for non-pecuniary features of alternative occupations, inter alia the risk that arises from pursuing the job. Occupations vary by health risk, risk of fatality, or unemployment and earnings risk. The theory predicts that workers opt for the occupation that maximizes their utility. Since the cost of bearing occupational uncertainty are lower for less risk averse individuals, their disutility of working in a risky job is also lower. Assuming that individuals sort into jobs accordingly, their choice reveals information regarding their risk attitude (controlling for all other relevant factors).

This sorting effect allows us to investigate whether intergenerational transmission of risk preferences is indeed reflected in children's and parents' occupation being similarly risky. A major asset of our analysis is that we are thus able to observe the risk connected to different generation's behavior in exactly the same context. By excluding child-parent pairs that work in exactly the same occupation, we rule out the possibility that the link is due to resembling preferences for a certain job instead of similarity in risk attitudes.

More precisely, we use the cross-sectional variation in monthly income that is not explained by human capital differences. This measure, proposed by McGoldrick (1995), has become the standard for measuring occupational earnings risk. Employing data from the 1991 to 2009 waves of the German Socio-Economic Panel (SOEP), we calculate the unexplained variation of income per occupation classified on a 3-digit-level of the International Standard Classification of Occupations (ISCO). The resulting values are assigned to 
children and parents, whose information we are able to merge.

The analysis shows that different generations of a family indeed exhibit similar risk behavior in exactly the same situation. We observe a significant relationship between fathers' and children's earnings risk. The effect is larger and more significant for sons. We find no significant relationship between mothers' and children's risk behavior. The lack of evidence does not necessarily imply that mothers exert no effect. The literature generally takes the risk measure employed in our study as being less reliable for females (McGoldrick 1995, Bonin et al. 2007). We address concerns regarding the calculation of the risk measure and the specificity of the transmission effect in the robustness checks and come to the same conclusions.

The remainder is organized as follows. In section 1, a review of the literature on intergenerational transmission of risk attitudes is given. The construction of the risk measure is described in section 2. The procedure and results of the empirical analysis of intergenerational transmission are reported in section 3, followed by a discussion of the robustness of our results in section 4. Section 5 concludes.

\section{Literature review}

In recent years, the assumption of exogenously given and stable risk preferences has been challenged. The endogeneity of preferences has become a major object of study. Bisin and Verdier (2005) emphasize that "preferences, beliefs, and norms that govern human behavior are formed partly as a the result of genetic evolution, and partly they are transmitted through generations and acquired by learning and other forms of social interactions." 1 Following this idea, several studies investigate the issue of intergenerational transmission of risk preferences.

In an attempt to explain correlation of wealth across generations, Charles and Hurst (2003) also investigate the correlation of self-reported risk toler-

\footnotetext{
${ }^{1}$ In the following, we refrain from a distinction between genetic and cultural inheritance. Our interest is in whether intergenerational transmission takes place at all and not via which channel it occurs.
} 
ance. Using data from the US Panel Study of Income Dynamics (PSID) the authors find evidence that children and their parents have similar preferences for income risk if their risk attitudes belong to one of the extreme risk categories. They find that stated risk preferences explain little of the propensity of parents and children owning the same assets. Charles and Hurst speculate that the similarity of children's and parents' actual choices is due to a tendency of children to mimic their parents' investment behavior. An alternative interpretation is that risk behavior revealed in a specific situation matters. The finding could also be interpreted as an indication that the informational content of responses to hypothetical gambles is limited.

Using the same dataset, Hryshko et al. (2011) principally confirm the results of a significant correlation between children's and parents' stated risk attitude. Unlike the previously described study, the parents' risk attitude only has a significant effect on children that are very risk averse (ca. $40 \%$ of sample) but not if the sample is limited to those that are extremely risk averse (ca. 20\% of sample). An explanation for the different finding compared to the previous study is that Hryshko and co-authors take into account the parents' schooling. They conclude that a direct effect from parental schooling to children's risk aversion exists. The authors further show that parents' risky behavior in the respondent's childhood, revealed via family business ownership, has a negative effect on a child's stated risk aversion.

In a similar vein, De Paola (forthcoming) shows that the riskiness of the father's but not of the mother's job (self-employment/public sector) matters for the child's risk aversion. Her analysis relies on responses of Italian students to a hypothetical lottery question and a question regarding the preferred job security. As an additional measure she uses students' answering behavior to an entry examination in which wrong answers are penalized. The regression results reveal that students whose fathers are entrepreneurs are less risk averse, while students whose fathers work in the public sector exhibit higher risk aversion. In contrast, mothers' employment status has no effect.

Arrondel (2009) studies intergenerational transmission using a measure of risk attitude created from 27 questions of the DELTA-TNS-Sofres Survey 
in France. He combines the questions, e.g., whether the respondents take precautions when weather turns out nasty or whether they buy plane or train tickets well in advance, as well as traditional lottery questions, in a qualitative risk score. Regressions of the child's preference score on the parents' one (mothers and fathers are not distinguished) reveal a positive relationship.

The study most closely related to ours is the one by Dohmen et al. (forthcoming). The authors provide evidence based on self-reported evaluations of risk preferences from the SOEP in which respondents are requested to assess on an 11-point scale: "How do you see yourself: Are you generally a person who is fully prepared to take risks or do you try to avoid taking risks?" They find that the responses of parents and children have a significantly positive relationship. This result is observed with respect to the general willingness to take risks as well as specific domains, i.e., financial matters, health, car driving, sports and leisure and career. The correlations between child's risk attitude with that of their mother and father slightly differ between the domains. For example, mothers and fathers seem to be similarly important for a child's attitude regarding career risk but fathers are more important with respect to health risk.

In short, intergenerational transmission of risk attitudes has been established based on stated preferences. Two of the studies utilize parents' employment status as a measure of risk attitude to explain the child's self-reported risk attitude. However, a thorough investigation of correlation between different generations' risk attitudes revealed by behavior is lacking.

\section{Risk attitudes - a revealed preference ap- proach}

\subsection{Advantages of a revealed preference measure}

The above analyses provide valuable insights into the question whether risk attitudes are transmitted between generations. An advantage of self-reported risk measures is that they offer an easy way to study people's attitudes. They 
suffer from a number of drawbacks, however, which suggest that analyzing the issue from a revealed preference perspective is a worthy exercise.

Common objections to stated measures are that the ordering and wording of questions, the low effort exerted on answering questions accurately, the desire of an individual to convey a certain impression, the absence of having an attitude, etc., bias the preferences reported by surveyed individuals (Bertrand and Mullainathan 2001). Furthermore, the framing of questions matters (Kahneman and Tversky 1981). Responses to hypothetical lottery questions involving a new job have been found to be driven by status quo bias (Kimball et al. 2009). A problem associated with risk attitudes on an 11-point scale - as requested in the SOEP - is that it is a qualitative measure which is not ideal for comparisons of the degree of risk aversion across individuals.

To alleviate such objections, Dohmen et al. (forthcoming) refer to another study by some of the authors (Dohmen et al. 2011) in which the behavioral relevance of the self-assessment of risk preference requested in the SOEP is tested in a complementary experiment. In this study, responses to a questionnaire are compared to behavior in paid real-stakes lotteries. The stated preferences are found to be a significant predictor of the riskiness of choices with real money at stake. The authors thus mitigate concerns regarding the reliability of the measure.

Nevertheless, analyses dealing with the consistency of individual's risk attitude across experimentally elicited measures and survey based ones yield contradictory results (e.g. Deck et al. 2008, Anderson and Mellor 2009). Ding et al. (2010) replicate the study by Dohmen et al. by comparing experimental behavior and survey responses of Chinese students. While the correlations between behavior and the stated measure resemble the ones reported by Dohmen et al. (2011), they conclude that stated risk attitudes only explain $10 \%$ of the variation in the real money situation. Similarly, while stated risk preferences have been found to be a significant determinant of actual risk taking behavior (such as smoking or investments), they only explain a small fraction of the variation in real world decisions (Barsky et al. 1997). 
Another issue is that risk attitudes have been found to be domain-specific (e.g. Weber et al. 2002, Deck et al. 2008). Using SOEP data, Dohmen et al. (2011) find that the best predictor of a certain behavior (e.g., holding financial assets or smoking), is the attitude of risk regarding that specific domain. Dohmen et al. (forthcoming) show that the parents' self-reported risk attitude in a specific domain best explains the child's attitude in that domain. However, even within domains differences might arise (Vlaev et al. 2010). For instance, an individual might be willing to take income risk but not health risk to proceed in her career. No existing survey measures capture such differences.

The described drawbacks can be avoided by using the approach traditionally employed in economics. Economists long insisted that inferences on people's preferences are only possible by observing their actual choices. With respect to their willingness to take risks, an individual's behavior on financial markets, the choice of sports, taking out insurances, or occupational choice is informative. In this study, we focus on the willingness to take risk associated with the choice of job. From an economist's perspective, behavior on labor markets is a particularly relevant issue. Another advantage is that a measure exists with which the willingness to take occupational risk can be quantified.

\subsection{Revealing risk attitudes by occupational choice}

According to standard economic theory, an individual chooses an occupation that maximizes his or her expected utility (Becker 1962). Utility from a certain job is assumed to be a function of wage, personal traits such as education and experience, as well as occupational features like working conditions or the exposure to different types of risk. The theory of compensating (or equalizing) wage differentials postulates that in a competitive labor market, unfavorable working conditions have to be compensated in order to attract workers (Rosen 1987). Higher risk of future income growth, unemployment, or health are thus reflected in a wage premium. Since the costs of bearing occupational uncertainty are lower for less risk averse individuals, the expectation of monetary compensation makes them more likely to opt for jobs 
connected to higher risk.

A rich body of empirical literature provides evidence for the existence of a wage premium. The issue is often analyzed by asking whether workers in occupations exposed to higher income risk are indeed compensated by higher wages. Early investigations employ the standard deviation or coefficient of variation of income within an occupation as a measure of risk (King 1974, Johnson 1977, Feinberg 1981, 1981a).

McGoldrick (1995) proposes another way of approximating earnings risk that dominates in the subsequent literature. The present study is based on this measure. First, a standard Mincer wage regression including education, experience and other characteristics (Mincer 1958, 1974) is estimated. The residual from that regression is exploited to calculate the variation in monthly income within an occupation or across time that is unexplained by observable differences in the individual's human capital stock. The measure is supposed to reflect the income uncertainty of an occupation from an ex ante perspective. It can therefore be taken as given when making the job decision. Using this measure, McGoldrick (1995), McGoldrick and Robst (1996), Hartog et al. (2003), Hartog and Vijverberg (2007) and other studies provide evidence that compensation of earnings risk in fact takes place.

Furthermore, several studies analyze occupational sorting according to risk attitudes. Ekelund et al. (2005) find that agents with a high score in a psychosometric indicator of risk attitude are more likely to be self-employed. Dohmen and Falk (2011) conduct a laboratory experiment that shows that risk averse workers prefer fixed payments and are less likely to sort into variable pay schemes. Pfeifer (2011), using SOEP-data, shows that individuals with relatively high stated risk aversion tend to sort into public sector employment. Similarly, Guiso and Paiella (2004) provide evidence from Italy showing that risk-prone individuals are more likely to be self-employed, be a business entrepreneur, and less likely to work in the public sector. DeLeire and Levy (2004) show that the risk of injuries has a considerable effect on an individual's choice of job.

In a study closely related to ours, Bonin et al. (2007) investigate whether the income risk an individual is willing to take matches his or her stated risk 
attitudes. As the dependent variable, the authors employ the risk measure proposed by McGoldrick (1995). Based on data from the SOEP, their analysis establishes a significantly positive relationship between a higher stated willingness to take risks and occupations with a higher unexplained variation of income. Hryshko et al. (2011) conduct the same analysis using data from the PSID and arrive at the same conclusion.

The theoretical considerations are thus substantiated by empirical evidence. By choosing an occupation in line with their willingness to take risks, individuals reveal their risk attitude. If risk attitude is transmitted from parents to children, we should be able to observe that they opt for similar risky occupations. We use this as our starting point.

\subsection{Construction of the risk measure}

In constructing a measure of earnings risk, we essentially follow the approach established in the literature. We first estimate a Mincer regression and calculate a measure of risk from the resulting residual. In contrast to previous studies that focus either on residual variation of income over time or across occupation, we consider both. We use the 1991 to 2009 waves of the SOEP to generate a measure that allows for variation across observed years within an occupation. The SOEP was first conducted in 1984 and expanded to East Germany in 1990. We include all waves from 1991 onwards (i.e., the year after full unification), to ensure that differences between the pre- and post-reunification period do not bias the results. In our view, the resulting measure is a representative indicator of the income risk an individual expects over the life course from an ex ante perspective.

For categorizing occupations, we use the International Standard Classification of Occupations (ISCO) provided by the International Labor Organisation $2^{2}$ This classification groups jobs by similarity of tasks and skills required. We employ the 3-digit-level of the ISCO88-code which is the second-most detailed level, sorting occupations into 116 groups. We calculate the un-

\footnotetext{
${ }^{2}$ For an extensive documentation see the website of the ILO: [http://www.ilo.org/public/english/bureau/stat/isco].
} 
explained variation of income by occupational groups for the total period considered. In the analysis, all occupations for which our dataset contains at least 100 observations are included. This leaves us with 85 different occupation groups for males and 62 for females $3^{3}$

Several adjustments of the raw data apply. The sample is restricted to adults between age 25 and 55 to avoid biases that may occur in the agerelated tails. We further exclude employees that are not employed full-time. The wages of part-time workers have a different variability and decisions are possibly made less consciously or based on different motives than full-time employment decisions (Constant and Zimmermann 2003). We also discard self-employed individuals as the determination of earnings in this sector is typically not comparable to the earnings of employees. Finally, we exclude implausible earnings information at the bottom of the distribution of net earnings by dropping the lowest 1-percentile in every year.

The Mincer regressions are estimated separately for women and men. A women's choice of job is more likely to be driven by factors that cannot be captured by the Mincer regression. McGoldrick (1995) finds that women have a lower percentage of earnings uncertainty attributable to systematic factors. The fact that female employment opportunities changed substantially over the last decades might also bias the results. Bonin et al. (2007) only calculate the measure for men. We include females in our analysis, however. While the risk measure might be somewhat noisy, a connection might still possibly exist.

In the specification of our Mincer regression, we follow the common approach. The dependent variable is the logarithm of the net monthly income of the individual $(\log N E T I N C)$. Our set of explanatory variables includes the human capital variables education $(E D U C)$ measured by years of schooling, experience $(E X P)$ measured by years of professional experience, and tenure $(T E N)$ measured by years of employment at the current employer. To capture decreasing returns to experience and tenure, we also include the second

\footnotetext{
${ }^{3}$ The substantial reduction in occupations is not reflected in an equivalent reduction in observations. We loose less than $2 \%$ of the male population and $5 \%$ of the female population. Employing the 4-digit level of the code would imply a much more substantial reduction of occupations and sample size.
} 
order polynomial of the last two variables. A binary variable indicating public sector employment is included to capture associated differences in income (PUBSEC). Summary statistics of those variables are displayed in table 1 in the appendix. As further controls, we include dummies for each occupation per 3 digit-ISCO code, thus controlling for the average payment level in that group, dummy variables indicating in which of the 16 German states the individual resides as well as time dummies. To account for heteroskedasticity, we employ robust standard errors.

Table 2 shows the results of the OLS regressions for males and females. The variables explain a large fraction of net monthly earnings. Coefficients are highly significant with signs as expected. Surprisingly, the effect of being employed in the public sector substantially differs between genders. Women employed in the public sector receive higher wages while the opposite effect is found for males. A possible explanation is that males and females work in different occupations, with typically female occupations being remunerated better in the public than in private sector.

From these estimates, we compute the measure of earnings risk as the standard deviation of the residuals in each occupational group where $j$ is the index indicating the ISCO sub-cell:

$$
\sigma_{j}=\operatorname{std}\left(e^{\hat{\varepsilon}_{j}}\right)
$$

For women, the variation of the resulting risk measure ranges from 0.22 to 0.42 with a mean of 0.27 and a standard deviation of 0.045 . The unexplained part of men's income varies between 0.19 and 0.47 with a mean of 0.29 and standard deviation of 0.064 . Gender differences hence seem to exist. The earnings risk found by Bonin et al. (2007) - which only applies to males - ranges from 0.2 to 0.8. An obvious explanation for those differences is that we employ a dataset spanning several years and thus containing many more observations than the dataset by Bonin et al. which only includes observations from one year. Estimating a pooled cross-section allows us to control for year-specific effects which lowers the unexplained variance. Hartog and Vijverberg (2007) show that annual measures are much noisier than risk 
measures based on several years.

The distribution of earnings risk is plausible. For males, the occupational category with the highest earnings risk is directors and chief executives (ISCO Code 121) and the one with the lowest encompasses police inspectors and detectives (345). For females, the highest income risk arises for health professionals (222) and the lowest for personal care workers (513). An important question is whether individuals of each skill level can choose between occupations connected to different degrees of risk. The relationship between income risk and skill-level of the occupation does not seem to follow a clear pattern. For each level of required skills/occupational task, occupations with different income risks are available. For instance, male "secondary education teaching professionals" (232) have an income risk of 0.28 while "other teaching professionals" who conduct research and develop or advise on teaching methods (235) have an income risk of 0.43 .

We investigate whether workers are actually compensated for bearing earnings uncertainty by adding the calculated risk measure in the Mincer regression. The results show that unexplained earnings variation has a large and significantly positive effect. The effect is higher for females than for males which is the same result obtained by McGoldrick (1995) 4. Since we are not interested in the exact impact of earnings risk on income we refrain from a rigorous analysis of the relationship.

\section{Intergenerational transmission of revealed risk preferences}

\subsection{Data}

For investigating intergenerational transmission of the willingness to take earnings risks, we construct a dataset from the SOEP waves of 2001 to 2009. To avoid inflating our dataset by including the same or similar information

\footnotetext{
${ }^{4}$ Occupation dummies at the 3-digit level are replaced by dummies at the 2-digit level. Obviously, the former drop out if we include them simultaneously with the job risk measure. Results available upon request.
} 
several times, we observe each child-parent pair only once. In case of multiple observations in different years, we keep the most recent observation. This has the advantage that children are older and occupational decisions presumably made more consciously.

An important restriction is that we drop children and parents working in exactly the same occupation. The intention is to rule out the possibility that similar preferences for a certain job rather than similarities in risk tolerance drive the decision. We ensure that the risk measure is representative for the individuals investigated by excluding individuals that are self-employed and following casual or part-time employment. The latter exclusion is less strict with respect to parents as we also include part-time workers. Parents might serve as a role model for occupational risk independent of their current hours worked. The distinction between full- and part-time workers, however, is only relevant for mothers. About half of the mothers included in our sample work part-time. Less than thirty (!) men have that status.

This leaves us with approximately 1500 children for which we also have information for mothers and fathers, respectively. Some explanatory variables are only available for fewer pairs so that the number of observations used in our regressions is lower in some models. The number of observations drops severely when we include both parents simultaneously. We therefore estimate separate regressions for mothers and fathers: $:^{5}$

\subsection{Descriptive analysis}

We merge the information obtained from Mincer regressions to child-parent pairs according to the 3-digit ISCO code of their occupation. The sample of parents as well as that of children contains individuals of the whole range of risk takers. Their earnings risk ranges from the lowest to the highest values, as can be seen in the upper panel of table 3. Means and variance are stable across generations and slightly larger for fathers and sons. In the lower panel, correlations between parents and sons and daughters are shown. Cor-

\footnotetext{
${ }^{5}$ Similar results are obtained when we include both simultaneously. Results available upon request.
} 
relations are highest between fathers' and sons' measure of risk, followed by the correlation between fathers and daughters. While mothers and daughters exhibit some similarity in the riskiness of the job chosen, sons' choices seem to rarely resemble the ones of their mothers. The correlations indicate that the relationship between fathers and sons is of particular interest.

Given the lively debate regarding the reliability and consistency of different types of risk measures (e.g. Anderson and Mellor 2009, Reynaud and Couture 2010), it is interesting to compare our measure to stated risk attitudes. In 2004 and 2009, SOEP respondents were asked to assess their general risk attitude as well as their risk attitude in specific domains, inter alia career issues, on a scale from 0 to 10 . We concentrate on responses from 2009 since most of our child-parent pairs were observed in that year ${ }^{6}$

Table 4 displays correlations between the risk measures obtained from the Mincer regressions with two statements regarding the willingnesses to take risks. In general, the risk preference revealed by occupational choice is more closely related to the self-reported risk attitude with respect to career than to general risk attitude, in line with the hypothesis of domain specific risk attitudes. A correlation between the measure obtained from real life decisions and those from stated preferences can clearly be established for sons and fathers. The correlation is lower for female members of the family. In particular, mothers' revealed and stated willingness to take risks differs. The low correlations are in line with previous research that finds that stated risk preferences only explain a small fraction of the variation in real world decisions (e.g. Barsky et al. 1997). We refrain from an in-depth analysis on the relationship which has already been provided by Bonin et al. (2007).

\subsection{Regression analysis}

\subsubsection{Methodology}

We are interested in whether the correlations between children's and parent's risk behavior, as shown in table 3 , can be confirmed when controlling for other determinants. We regress the child's risk variable on the parent's one using

\footnotetext{
${ }^{6} \mathrm{~A}$ comparison to values from 2004 gives similar results.
} 
four different specifications. Model 1 is a bivariate regression without any controls. Model 2 adds personal and labor-market-related variables of the child except for its income. This variable is added in model 3 so that we can examine whether the results are biased due to endogeneity in model 2. In the fourth specification, we include the parent's characteristics. Equation 2 shows the (comprehensive) model of our transmission regressions:

$$
R I S K_{i}=\alpha+\beta_{1} P R \_R I S K_{i}+\beta_{2} X_{i}+\beta_{3} \log N E T I N C_{i}+\beta_{4} P R \_X_{i}+\varepsilon_{i}
$$

The dependent variable is the earnings risk associated with the child $i$ 's occupation $(R I S K)$ which is assigned according to the 3-digit ISCO code of the occupation. Our main variable of interest is the earnings risk of the parent's current occupation $\left(P R_{-} R I S K\right) . P R_{-} R I S K$ is either the mother's or father's risk measure (indicated in the tables). Provided that intergenerational transmission of risk attitudes takes place and is reflected in the riskiness of the job chosen being similar, the parent's job risk should be positively related to the child's job risk.

In various studies, risk preferences have been found to be related to personal and socio-economic characteristics (e.g. Barsky et al. 1997, Hartog et al. 2002, Eckel and Grossman 2008, Dohmen et al. forthcoming, 2011). To control for such effects, we add a variety of explanatory variables in model two (included in $X$ ). First of all, we include the age of the child in the respective year $(A G E)$. Previous research finds that older individuals have a lower risk tolerance. Gender seems to play an important role, with women being more risk averse than men (FEMALE). A dummy for being married $(F A M I L Y)$ captures effects on the willingness to take risk that can arise from such a commitment. Individuals that are healthy might be more inclined to take income risks. HEALTH measures an individual's self assessment of his or her status on a 5-point-scale. Additionally, we include dummies for religion.

Furthermore, we control for other factors that determine occupational 
sorting. The (riskiness of the) occupation chosen should be influenced by the individual's years of schooling $(E D U C)$. Well-educated individuals are likely to recover from failures more easily. Education has also been found to have an effect on risk attitudes. Besides, the duration at an employer could have an influence $(T E N)]^{7}$ In Germany, working in the public sector is usually connected to a more stable development of income. We thus include a dummy indicating whether the individual is employed in the public sector (PUBSEC).

Since the historical and economic environment varies between the two parts of Germany, a binary variable for living in the eastern part of Germany $(E A S T)$ is included. While empirical studies find limited evidence for significant differences in the willingness to take risks (Dohmen et al. 2011, Bonin et al. 2007, Heineck and Süssmuth 2011), the labor market situation differs considerably.

The risk taken in an occupation should also be related to the compensation received for it, i.e., the individual's income. Risk aversion in general has been found to be related to income and wealth. While some studies find a negative relationship (e.g. Hartog et al. 2002), Barksy et al. (1997) show that the willingness to take risks increases in income and wealth until the middle of the distributions, and then decreases. Given the potential endogeneity of this variable, we include the net monthly income in $\operatorname{logs}(\log N E T I N C)$ only in some specifications.

Furthermore, controls for family background are required (included in $\left.P R \_X\right)$. Since we estimate separate regressions for mothers and fathers, the control variables contain information for mother or father, respectively. As such, we include the parent's years of education $\left(P R_{-} E D U C\right)$, his or her age $\left(P R_{-} A G E\right)$, whether he or she is married $\left(P R_{-} F A M I L Y\right)$ and works in the public sector $\left(P R_{-} P U B S E C\right)$. The net household income of the parental household $\left(P R_{-} \log H H I N C\right)$ is included as a proxy for the wealth of a family. In addition, we control for the residence during the first 15 years of life of the parents (big city, small city, small town, countryside, missing) to

\footnotetext{
${ }^{7}$ It is not controlled for experience. Due to the young age of children, the variable is highly correlated with experience and age.
} 
take into account risk-related effects that stem from growing up in a certain environment. While it would be interesting to also include this information for the child, the data is largely unavailable. The parent's residence of youth might yet serve as a proxy if the family lived or moved to the same type of region when the child was young. Summary statistics are given in table 5 in the appendix.

We estimate the models using ordinary least squares (OLS) and include dummies for the wave from which the observation is drawn in all regressions 8 To take into account heteroskedasticity, all hypothesis tests are calculated using robust standard errors.

\subsubsection{Regression results}

Regressions including all children The results of the OLS estimates can be found in table 6. In regressions including the fathers' earnings risk, the coefficient on the main variable of interest is positive as expected. In all models, the effect of fathers' risk measure is significant at the $1 \%$ level. The magnitude of the effect drops once we include children's characteristics. Extending the model by the potentially endogenous income of the child or fathers' characteristics does not change results. Interestingly, the coefficient obtained by Dohmen et al. (forthcoming) in the regressions of the child's stated career risk attitude on their fathers' one (taking into account the specificity of intergenerational transmission) is of equal magnitude. No significant effect can be found in regressions of the child's risk measure on the mothers' one. The coefficient is insignificant in all regressions.

To interpret the size of the fathers' effect, we multiply the coefficient from the fourth model with the standard deviation of the fathers' risk measure. An increase in the father's income risk by one standard deviation increases the risk measure by 0.004. A comparison to absolute differences of earnings risk between occupations (in order of increasing values) puts this number into perspective. The mean difference of the risk measure between occupations is 0.002. Accordingly, an increase of father's earnings risk by one standard

\footnotetext{
${ }^{8}$ Re-estimating the models with ordered probit yields similar results. Results available upon request.
} 
deviation implies that the child opts for a job with an income risk that is two ranks higher (if all jobs are ordered according to risk).

Concerning the other control variables some further results are notable. Daughters have a lower earnings risk, as already indicated by descriptive statistics. Years of education are quantitatively and statistically highly significant drivers of occupational risk tolerance. Tenure and working in the public sector decrease the riskiness of job. None of the parents' controls enters with significance.

Regressions by gender of children Given the insignificance of the mothers' risk measure, the question arises whether the effect parents have on daughters also differs from the effect on sons. We thus split the sample by children's gender. The results from the regressions are shown in table 7. As can be seen, we find a larger correlation between fathers' and sons' risk compared to the regressions including children of both genders. However, a t-test shows that the difference is not significant. The effect of fathers on daughters is smaller and only significant if no other control variables are included.

Mothers neither have an effect on sons nor on daughters. Three possible explanations for this results are conceivable. First of all, the insignificant results might indicate that children's risk behavior is not based on their mother's function as a role model. Secondly, as many mothers also face other obligations, their current occupational choice is likely to be driven by other factors than risk. If mothers' actual risk attitude and the riskiness of their job are thus little related (as is indicated by the particularly low correlation between stated and revealed measures), this might explain why we are unable to establish a relationship. The third and most plausible explanation is that the risk measure is more representative with respect to males. If the approximation of earnings risk is less precise for females it is difficult to establish a relationship. A similar explanation might apply as to why we also only find very weak evidence for daughters' and fathers' occupational risk being correlated. 


\section{Robustness Checks}

The robustness of our results can be challenged in different respects. On the one hand, the calculation of the risk measure might be of concern. We check the robustness by calculating different modifications. A comparison of all resulting risk measures is given in table $9 \square^{9}$ Furthermore, the robustness of the transmission effect might raise questions. We try to address these issues with additional tests.

In the following, we focus on the fathers' effect and additionally report results from regressions only including sons. We checked whether mothers have a significant effect for all specifications and obtained the same results as in the main regressions, i.e., a smaller and insignificant effect.

\subsection{Robustness of risk measure}

Taking into account the relative nature of income risk The theory of compensating wage differentials postulates that workers are compensated for bearing risks, in our case unsystematic variation of income. As has been described above, workers that are less risk averse are more likely to opt for such occupations in expectation of the compensation they will earn. This is the very basis for the approach of this study. One might, however, argue that, if only compensation is sufficient, all workers are willing to accept a risky job. To exclude such effects, we control for an individual's income in some of the specifications above and find that income has no effect on the willingness to take income risks. Nevertheless, the variable is potentially endogenous making it difficult to unambiguously identify effects.

An alternative is to already consider income when calculating the risk measure. We divide the variation of the residual, i.e., the previously employed risk measure, by the mean of log income in the respective occupation to account for the relative nature of income risk. As before, the male income risk is higher than the female income risk on average; the same holds for the standard deviation, as can be seen in table 9 .

\footnotetext{
${ }^{9}$ Results on all Mincer regressions are not reported. Available upon request.
} 
The set of control variables is the same as in the baseline regression except for the income variables, which are not included. We thus estimate models 1,2 and 4 described in the previous section. In table 8, the results of the regressions of children's risk on fathers' risk as well as sons' on fathers' risk are shown. As can be seen, the results strongly resemble the results obtained in the baseline regressions. Since income is now already considered in the risk measure, the bivariate regression reveals a slightly lower correlation. If the other control variables are added, the same effect is found as before. As in the previous regressions, the correlation is larger between fathers and sons.

Private versus public sector As has already been indicated in the discussion of control variables for the Mincer regression, payment structures in public and private sector employment differ in Germany. In the public sector, the conditions of employment are regulated by federal and state laws. Payment schemes are more strongly standardized and salary increases due to age, tenure and the family situation rather than performance. The significant coefficient in the transmission regressions in the previous section indicates that differences in income risk in fact exist.

To capture the differences more precisely, we split the sample into employees that are employed in the private and public sector and re-estimate Mincer regressions as described in section 2.3 with the sole difference that the public sector dummy is dropped. A consequence of splitting the sample is that we are only able to calculate a risk measure for fewer occupations, i.e., for males (females) for 66 (50) groups in private and for 39 (28) in public employment. As expected, the mean unexplained variation of income is lower in the public sector. Gender differences in the mean occupational risk are smaller for public servants. We assign the risk measure to family members according to their occupation and whether they work in the public sector or not.

Due to the consideration of employment status in the calculation of the risk measure it is unnecessary to control for public/private sector employment. In table 10, the results on the intergenerational transmission regressions using separate risk measures for public and private sector are shown. 
The results largely resemble the results obtained with one combined measure for private and public sector employment. The magnitude of the coefficient on the father's risk slightly differs from the one obtained in the baseline regressions, even though the difference is not significant. The significance of the coefficient drops to the $5 \%$ level (10\% in regressions on sons' risk) once we take the fathers' characteristics into account. A possible explanation is that the risk measure, in particular the one for public sector employees, is now calculated using fewer observation, which makes it subject to a larger variation.

The Mincer residual - a measure of risk versus ability A possible objection to the risk measure is that the residual captures a variety of unobservable factors besides compensation for occupational risk. In particular, ability is presumed to be an important determinant of earnings that can hardly be observed in large-scale surveys. The Mincer residual in fact has also been employed as a measure of ability. However, the calculation differs. The Mincer residual as a proxy for ability is used in its pure form, i.e., the residual generated in the regressions is employed in the analysis (e.g. Mwabu and Schultz 1996). In contrast, if the Mincer residual is employed as a measure of risk the variance of the residual over several individuals is calculated - as has extensively been described above. This ensures that the measure is largely detached from individual ability.

In order to remove remaining doubts, we searched for a proxy for an individual's ability to be included in the Mincer regression. In the SOEP interviews, measures of cognitive ability have recently been added but are only available for a minor number of respondents. The only measure that is available at a larger scale, though still only for a quarter of the observations used in the baseline Mincer regressions, are the grades received during school. Grades have been requested in the biography questionnaire for persons entering SOEP since 2001 ("What grade or points did you get in your last report card"). While this is of course an insufficient indicator of ability, it at least seems qualified to be used as a proxy.

We thus include the mean of the individuals' grades in mathematics and 
German lessons into the baseline Mincer regressions. As expected, the results indicate that better grades in high school have a positive impact on an individual's income. The number of occupations for which we are able to calculate the variation of unexplained income drops from 85 (62) categories to 47 (23) categories for male (female). To identify whether differing samples matter for the calculation of the Mincer residual, we re-estimate the Mincer regressions based on the sample for which we observe the reported grades but exclude the grades as an explanatory variable. The two new risk measures are almost the same with slightly lower values if ability is included. This is not surprising, as now a larger fraction of the wage variance is explained. Compared to the average risk measure from baseline Mincer regressions, the new measures show an increase of mean and variance for men.

As a consequence of the reduced availability of the risk measures, the number of father-child pairs in the transmission regressions is significantly reduced. The results of the regressions using the modified risk measure controlling for ability via grades during school can be found in the upper half of table 11. As before, we find a significantly positive effect of the fathers on children and sons, respectively. The influence is, however, slightly lower in magnitude and in significance. The effect is similarly high in all models. Comparing the results to the lower half of table 11 in which the comparative measure is included shows large similarities with nearly identical coefficients for the child-father transmission. The differing results from the inclusion of the grades into the Mincer regressions thus seem to be driven by the reduced sample. Even so, we have to acknowledge that grades may not be a good proxy for ability and success in one's career.

Limiting sample to West Germany Due to the fact that East Germany only became part of the Federal Republic in 1990, we restricted the sample for the calculation of the risk measure to 1991 to 2009 in the above regressions. Furthermore, we include a dummy for East German inhabitants to control for differences in wages and risk taking. However, the occupational choice of East Germans that started their career under socialism might be different. Riskiness of job was much less an issue and politics severely influenced the 
choice of job. Fuchs-Schündeln and Schündeln (2005) argue that self-selection due to risk aversion was absent in the German Democratic Republic. Due to path-dependency, the current job of East Germans might not reflect the riskiness that they are willing to bear.

We thus limit the sample employed for the calculation of the Mincer residual as well as for the transmission regressions to West Germans. In the regressions, we drop the East German dummy. With the exclusion of East Germans, the number of occupations for which we are able to calculate the risk measure is reduced to 75 for males and for females to 51 . The mean income risk is slightly lower and varies to a larger extent for men.

The transmission dataset is reduced by up to 475 pairs. The regression results can be found in table 12 . They show an even stronger influence of fathers on their children, especially on their sons. Compared to our baseline results in table 6 and table 7 , all coefficients are higher in the regressions with only West Germans. Nevertheless, t-tests reveal that the differences are not statistically significant. These results thus indicate that the transmission effect partly seems to be driven by the strong correlation of West German parents and their children.

Stability of the risk measure over time A problem is that we cannot observe the distribution of earnings risk in the year in which the respondents chose their occupation. As a global measure of the income risk perceived from an ex ante point of view, the measure calculated using the full period thus seems to be the most reliable. However, it is possible that the earnings risk changes over time (for example due to shocks or structural changes in the economy) and individuals are constrained in continuous optimization (for example due to incomplete information, cognitive limitations, transaction costs). Observed choices then do not necessarily reflect the underlying preferences. Given path-dependencies, individuals from the parent generation might work in an occupation that is connected to another risk today then it was when they decided. Parents might yet transmit the risk attitude on which the decision was based.

For this reason, we calculate separate risk measures for the two decades 
that our sample for Mincer regressions covers. We observe a drop in the number of occupations in particular for the measure from the earlier period. A comparison of the mean of income risk in the period from 1991 to 1999 compared to a measure calculated from the years of 2000 to 2009 shows an increase in unexplained variation of income over time (significant at the 5\%-level).

We attach the risk measure calculated from the subsample from 1991 to 1999 to parents. Children are assigned the occupational risk calculated using the subsample from 2000 to 2009 . We thereby account for parents and children making their job choices at different times. This is of course a crude approach as the decision made by parents and children might well have been made in another period. The upper panel of table 13 displays the regressions results. The baseline results are confirmed, albeit a decrease in significance and magnitude can be observed.

The results might be explained by children considering the current occupational risk of their parents. Furthermore, lacking optimization might not be an issue. Since the job choice of all individuals is observed in the period 2000 to 2009, the risk distribution based on the sample from 2000 to 2009 might be more appropriate. The lower panel of table 13 displays the regression results with the more recent risk measure assigned to parents and children. The result resemble the findings of the baseline regressions to a larger extent, with only slightly smaller coefficients.

\subsection{Robustness of transmission effect}

Influence of parents' first job on children In the above regressions, we observe the current choice of job of parents and children. An interesting aspect is whether parents' and children's risk behavior is alike at a similar stage in their life, i.e., when they are about the same age, have the same family status etc. A possibility is to compare the risk associated with the job pursued early in career. The SOEP provides information on the parents' first job.

We are therefore able to compare the riskiness of the children's job - which 
are presumably in an early stage of their career - with the parents' riskiness of first job. The set of parental control variables that is included in the fourth model differs slightly. The dataset contains information on the age at first job, whether the individual was self-employed or employed in the public sector and whether he was working full-time. We exclude parents that were self-employed and not working full-time in their first job and control for the other two variables and the residence in youth to ensure comparability with previous regressions. Information for education, family status and household income at the parents' first job is not available. Since these variables did not show a significant effect, this should be of little concern.

The information is available for about 1600 fathers, 400 of which are still working in their first job. On average, fathers are 19.11 years old when taking up their first job. We assign the risk measure from the total period to parents according to the ISCO code of their first occupation. The mean income risk is lower in the first job (0.2668) than in the current job (0.2850). A comparison reveals stability of riskiness of job choice; the correlation between fathers' first and current job risk is 0.35 . Taking into account that risk aversion changes over the life cycle, this is a remarkable correlation.

Table 14 shows the regression results including the income risk of the fathers' first job as the main explanatory variable. The results of the regressions including all children are largely similar to the ones obtained in regressions with the current level of job. A drop of significance of the coefficient on the variable of main interest to the $5 \%$-level is observed in the fourth model. If the sample is split by gender and only sons observed, coefficients resemble those previously found while significance of the relationship drops in models 2 to 4 . Interestingly, the influence of fathers on daughters is significant for models 1 to 3 (not reported, available upon request). An ad hoc explanation is that daughters more often remain stuck in their first job while sons already proceeded to a later career level when observed in our sample. Fitzenberger and Kunze (2005) show that occupational mobility is lower for women than for men. 
Transmission in different age groups Another question is whether children of all age groups are equally influenced by their parents' willingness to take income risks. Younger children might work in an occupation which is only one step of the career path necessary to proceed to the occupation in which they actually aim to work in - and which represents the riskiness they are willing to take. As has been described in the previous paragraph, three fourths of the fathers currently do not work in the occupation they named as their first job. In contrast, comparatively older children are more likely to work in their favored occupation. This is supported by Bonin et al. (2007) who find that the sorting effect according to risk preferences is stronger for individuals with more years of experience.

We split the sample by the age of 25 which is the mean age in our sample and also a reasonable age for having completed education. Furthermore, the risk measure has been calculated from individuals older than 25. Results are shown in table 15. As can be seen, the relationship between fathers' and children's income risk is much weaker and at most significant at the 10\%level for children younger than 25. In contrast, the relationship between the riskiness of the job choice by children that are 25 or older and the one by their fathers' is larger than in the baseline regressions and is significant. The same changes can be observed in regressions based on sons only. Accordingly, children sort into occupations with an income risk similar to their parents' one at a later stage of life.

\section{Conclusion}

The determinants of risk preferences are an important concern in economic research. In particular, the question has been raised whether risk preferences are transmitted between generations. Prior research shows that children of more risk-tolerant parents describe themselves as having similar preferences. The present paper contributes to this line of research by providing the first evidence based on a real and major economic decision: the choice of occupation. We investigate whether children show a similar willingness to take income risks like their parents. Given the controversy regarding the appro- 
priate measurement of risk attitudes, it is of substantial interest to study whether previous results can be confirmed based on observed risk taking behavior. An important advantage of the approach is that we can study whether children and parents also show similar risk preferences in exactly the same situation.

To rule out the possibility that the link is due to resembling preferences for a certain job instead of similarity in risk attitudes, children and parents working in exactly the same occupation are excluded. We find a highly significant transmission effect from fathers to children, in particular to sons. No significant effect is found for mothers. One explanation is that the formation of risk preferences is not influenced by the mothers' risk attitudes. However, the literature generally takes the employed risk measure as being less reliable for women. A variety of robustness checks provide broad support for these findings.

Based on a major economic decision, our study thus confirms intergenerational transmission of risk attitudes. Family members of different generations not only respond similarly but also behave accordingly.

\section{References}

[1] Anderson, L.R., J.M. Mellor (2009). Are Risk Preferences Stable? Comparing an Experimental Measure with a Validated Survey-based Measure, Journal of Risk and Uncertainty, 39, 2, 137-160.

[2] Arrondel, L. (2009). "My Father was Right": The Transmission of Values between Generations, HAL-PSE Working Papers, 2009-12.

[3] Barsky, R.B., F.T. Juster, M.S. Kimball, M. D. Shapiro (1997). Preference Parameters and Behavioral Heterogeneity: An Experimental Approach in the Health and Retirement Study, Quarterly Journal of Economics, 112(2), 537-579.

[4] Becker, G.S. (1962). Investment in Human Capital: A Theoretical Analysis, Journal of Political Economy, 70, 5-14.

[5] Bertrand, M., S. Mullainathan (2001). Do People Mean What They Say? Implications for Subjective Survey Data, The American Economic Review, 91(2), 67-72. 
[6] Bisin, A., T. Verdier (2005). Cultural Transmission. In: S. N. Durlauf, L. E. Blume (eds.), The New Palgrave Dictionary of Economics, 2nd Edition. Palgrave Macmillan.

[7] Bonin, H., T. Dohmen, A. Falk, D. Huffmann, U. Sunde (2007). CrossSectional Earnings Risk and Occupational Sorting: The Role of Risk Attitudes, Labour Economics, 14(6), 926-937.

[8] Charles, K. K., E. Hurst (2003). The Correlation of Wealth Across Generations, Journal of Political Economy, 111(6), 1155-1182.

[9] Constant, A., K. Zimmermann (2003). Occupational Choice Across Generations, Applied Economics Quarterly, 49(4), 299-317.

[10] Deck, C., J. Lee, J. Reyes, C. Rosen (2008). Measuring Risk Attitudes Controlling for Personality Traits, University of Arkansas, Florida International University, mimeo.

[11] DeLeire, T., H. Levy (2004). Worker Sorting and the Risk of Death on the Job, Journal of Labor Economics, 22(4), 925-953.

[12] De Paola, M.. The Determinants Of Risk Aversion: The Role Of Intergenerational Transmission, Universitá della Calabria, Dipartimento di Economia e Statistica, Working Paper, 16 - 2010. (forthcoming in: German Economic Review)

[13] Ding X., J. Hartog, K. Sun (2010). Can We Measure Individual Risk Attitudes in a Survey? IZA Discussion Paper, 4807.

[14] Dohmen, T., A. Falk (2011). Performance Pay and Multi-dimensional Sorting: Productivity, Preferences and Gender, American Economic Review, 101(2), 556-90.

[15] Dohmen, T., A. Falk, D. Huffman, U. Sunde, J. Schupp, G. G. Wagner (2011). Individual Risk Attitudes: Measurement, Determinants, and Behavioral Consequences, Journal of the European Economic Association, $9(3), 522-550$

[16] Dohmen, T., A. Falk, D. Huffman, U. Sunde. Intergenerational Transmission of Risk and Trust Attitudes, IZA Discussion Papers, 2380. (forthcoming in: Review of Economic Studies).

[17] Eckel, C. C., P. J. Grossman (2008). Men, Women and Risk Aversion: Experimental Evidence. In: Handbook of Experimental Economics Results, Volume 1, C. R. Plott, V. L. Smith (eds.), North Holland. 
[18] Ekelund, J., E. Johansson, M.-R. Jrvelin, D. Lichtermann (2005). SelfEmployment and Risk Aversion: Evidence from Psychological Test Data, Labour Economics, 12(5), 649-659.

[19] Guiso, L. and M. Paiella (2004). The Role of Risk Aversion in Predicting Individual Behavior, mimeo.

[20] Feinberg, R. (1981). Earnings-Risk as a Compensating Differential, Southern Economic Journal, 48(1), 156-163.

[21] Feinberg, R. (1981a). Employment Instability, Earnings and Market Structure, Applied Economics, 13(2), 257-265.

[22] Fitzenberger, B., A. Kunze (2005). Vocational Training and Gender: Wages and Occupational Mobility among Young Workers, Oxford Revies of Economic Policy, 21(3), 392-415.

[23] Fuchs-Schündeln, N., M. Schündeln (2005). Precautionary Savings and Self-Selection: Evidence from the German Reunification "Experiment", Quarterly Journal of Economics, 120(3), 1085-1120.

[24] Hartog, J., A. Ferrer-i-Carbonell, N. Jonker (2002). Linking Measured Risk Aversion to Individual Characteristics, Kyklos, 55(1), 3-26.

[25] Hartog, J., E. Plug, L. Diaz-Serrano, J. Vieira (2003). Risk Compensation in Wages - A Replication, Empirical Economics, 28(3), 639-647.

[26] Hartog, J., W.P.M. Vijverberg, (2007). On Compensation for Risk Aversion and Skewness Affection in Wages, Labour Economics, 14(6), 938956.

[27] Heineck, G., B. Süssmuth (2010). A Different Look at Lenin's Legacy: Trust, Risk, Fairness and Cooperativeness in the Two Germanies, IZA Discussion Paper, 5219.

[28] Hryshko, D., M. J. Luengo-Prado, B. E. Sørensen, B.E. (2011). Childhood Determinants of Risk Aversion: The Long Shadow of Compulsory Education, Quantitative Economics, 2 (1), 37-72.

[29] Johnson, W. (1977). Uncertainty and the Distribution of Earnings. In: The Distribution of Economic Well-Being, edited by F.T. Juster (Ballinger, Cambridge, MA), 379-396.

[30] Kahnemann, D., A. Tversky (1981). The Framing of Decisions and the Psychology of Choice, Science, 211(4481), 453-458. 
[31] King, A.G. (1974). Occupational Choice, Risk Aversion, and Wealth, Industrial and Labor Relations Review, 27(4), 586-596.

[32] Kimball, M. S., C. R. Sahm, M. D. Shapiro (2009). Risk Preferences in the PSID: Individual Imputations and Family Covariation, American Economic Review, 99(2), 363-68.

[33] McGoldrick, K. (1995). Do Women Receive Compensating Wages For Earnings Risk? Southern Economic Journal, 62(1), 210-222.

[34] McGoldrick, K., J. Robst (1996). The Effect of Worker Mobility on Compensating Wages for Earnings Risk, Applied Economics, 28(2), 221232.

[35] Mincer, J. (1958). Investment in Human Capital and Personal Income Distribution, The Journal of Political Economy, 66(4), 281-302.

[36] Mincer, J. (1974). Schooling, Experience and Earnings, NBER, New York.

[37] Mwabu, G., P. Schultz (1996). Education Returns Across Quantiles of the Wage Function: Alternative Explanations for Returns to Education by Race in South Africa, American Economic Review, 86(2), 335-339.

[38] Pfeifer, C. (2011). Risk Aversion and Sorting into Public Sector Employment, German Economic Review, 12(1), 85-99.

[39] Reynaud, A., S. Couture (2010). Stability of Risk Preference Measures: Results From a Field Experiment on French Farmers, TSE Working Paper Series, 10-151.

[40] Rosen, S. (1987). The Theory of Equalizing Differences. In: O. Ashenfelter, R. Layard, Handbook of Labor Economics, 1, 641-688.

[41] Vlaev, I., P. Kusev, N. Stewart, S. Aldrovandi, N. Chater (2010). Domain Effects and Financial Risk Attitudes, Risk Analysis, 30, 9.

[42] Weber, E. U., A.-R. Blais, N. E. Betz (2002). A Domain-Specific RiskAttitude Scale: Measuring Risk Perceptions and Risk Behaviors, Journal of Behavioral Decision Making, 15, 1-28.

\section{Appendix}


Table 1: Summary statistics Mincer regression

\begin{tabular}{|r|c|r|r|r|r|}
\hline & obs & Mean & Std. Dev. & Min & Max \\
\hline Males & & & & & \\
logNETINC & 67563 & 7.40 & 0.44 & 4.25 & 10.31 \\
EXPB & 67563 & 17.80 & 9.17 & 0 & 40 \\
TEN & 67563 & 11.03 & 9.24 & 0 & 42.3 \\
EDUC & 67563 & 12.23 & 2.71 & 7 & 18 \\
PUBSEC & 67563 & 0.22 & 0.41 & 0 & 1 \\
\hline Females & & & & & \\
$\operatorname{logNETINC}$ & 31882 & 7.10 & 0.41 & 4.70 & 9.90 \\
EXPB & 31882 & 14.90 & 9.08 & 0 & 40 \\
TEN & 31882 & 9.74 & 8.51 & 0 & 40.8 \\
EDUC & 31882 & 12.55 & 2.72 & 7 & 18 \\
PUBSEC & 31882 & 0.37 & 0.48 & 0 & 1 \\
\hline
\end{tabular}

Table 2: Mincer Regressions

\begin{tabular}{lcc}
\hline \hline Variable & $\begin{array}{c}\text { Male } \\
\mathrm{b} / \mathrm{se}\end{array}$ & $\begin{array}{c}\text { Female } \\
\mathrm{b} / \mathrm{se}\end{array}$ \\
\hline EXPB & $0.032^{* * *}$ & $0.022^{* * *}$ \\
& $(0.001)$ & $(0.001)$ \\
EXPB2BY100 & $-0.069^{* * *}$ & $-0.047^{* * *}$ \\
& $(0.001)$ & $(0.002)$ \\
TEN & $0.010^{* * *}$ & $0.011^{* * *}$ \\
& $(0.000)$ & $(0.001)$ \\
TEN2BY100 & $-0.016^{* * *}$ & $-0.017^{* * *}$ \\
& $(0.001)$ & $(0.002)$ \\
EDUC & $0.038^{* * *}$ & $0.039^{* * *}$ \\
& $(0.001)$ & $(0.001)$ \\
PUBSEC & $-0.043^{* * *}$ & $0.028^{* * *}$ \\
& $(0.004)$ & $(0.004)$ \\
Intercept & $6.428^{* * *}$ & $6.407^{* * *}$ \\
& $(0.033)$ & $(0.038)$ \\
3 digit-ISCO dummies? & YES & YES \\
STATE dummies? & YES & YES \\
TIME dummies? & YES & YES \\
\hline \multicolumn{3}{c}{} \\
\hline $\mathrm{N}$ & 67563 & 31882 \\
F & 699.891 & 414.435 \\
\hline \hline
\end{tabular}

Significance levels : $\quad *: 10 \% \quad * *$ : $5 \% \quad * * *: 1 \%$. Dependent variable: $\log$ monthly income of the respondent.

Table 3: Descriptive statistics of risk measure for all family members

\begin{tabular}{|l|c|c|c|c|c|}
\hline & Obs & Mean & Std.Dev. & Min & Max \\
\hline Risk fathers & 2114 & 0.2812 & 0.0498 & 0.1879 & 0.4688 \\
Risk mothers & 2101 & 0.2575 & 0.0302 & 0.2177 & 0.4191 \\
Risk sons & 1697 & 0.2817 & 0.0476 & 0.1879 & 0.4688 \\
Risk daughters & 1217 & 0.2615 & 0.0378 & 0.2177 & 0.4191 \\
\hline
\end{tabular}

\begin{tabular}{|l|c|c|}
\multicolumn{2}{c}{} & \multicolumn{2}{c|}{ Correlations } \\
\hline & with sons & with daughters \\
\hline Fathers & 0.1756 & 0.1084 \\
Mothers & 0.0300 & 0.0488 \\
\hline
\end{tabular}


Table 4: Correlations between stated and revealed risk attitude

\begin{tabular}{|r|c|c|}
\hline & $\begin{array}{c}\text { Stated "career" } \\
\text { with revealed }\end{array}$ & $\begin{array}{c}\text { Stated "general" } \\
\text { with revealed }\end{array}$ \\
\hline Fathers & 0.131 & 0.0619 \\
Mothers & 0.0254 & 0.0106 \\
Sons & 0.0996 & 0.036 \\
Daughters & 0.0567 & 0.0212 \\
\hline
\end{tabular}

Table 5: Summary statistics for transmission regressions

\begin{tabular}{|c|c|c|c|c|c|}
\hline Variable & Obs & Mean & Std. & Min & Max \\
\hline $\mathrm{AGE}$ & 2836 & 25.6090 & 5.7598 & 17 & 47 \\
\hline FEMALE & 2836 & 0.4193 & 0.4935 & 0 & 1 \\
\hline MARRIED & 2835 & 0.1266 & 0.3326 & 0 & 1 \\
\hline HEALTH & 2829 & 2.1184 & 0.7797 & 1 & 5 \\
\hline EDUC & 2550 & 11.9422 & 2.5089 & 7 & 18 \\
\hline EXP & 2833 & 3.6551 & 4.7363 & 0 & 25.8 \\
\hline TEN & 2836 & 3.5349 & 3.8474 & 0 & 25.4 \\
\hline PUBSEC & 2791 & 0.1834 & 0.3871 & 0 & 1 \\
\hline PROTESTANT & 2836 & 0.2236 & 0.4167 & 0 & 1 \\
\hline RELAND & 2836 & 0.0402 & 0.1965 & 0 & 1 \\
\hline NORELIGION & 2836 & 0.2073 & 0.4055 & 0 & 1 \\
\hline RELMISS & 2836 & 0.3170 & 0.4654 & 0 & 1 \\
\hline CATHOLIC & 2836 & 0.2119 & 0.4087 & 0 & 1 \\
\hline EAST & 2836 & 0.2507 & 0.4335 & 0 & 1 \\
\hline logNETINC & 2826 & 6.7787 & 0.6883 & 3.7842 & 9.1050 \\
\hline \multicolumn{6}{|l|}{ Father } \\
\hline VAGE & 2005 & 53.2110 & 6.7127 & 34 & 78 \\
\hline VEDUC & 1976 & 11.9509 & 2.4525 & 7 & 18 \\
\hline VMARRIED & 2005 & 0.9122 & 0.2830 & 0 & 1 \\
\hline VPUBSEC & 1939 & 0.1949 & 0.3963 & 0 & 1 \\
\hline VlogHHINC & 1889 & 8.0765 & 0.4859 & 6.2146 & 10.2647 \\
\hline VGREWLCITY & 2005 & 0.0623 & 0.2418 & 0 & 1 \\
\hline VGREWMCITY & 2005 & 0.0354 & 0.1849 & 0 & 1 \\
\hline VGREWSCITY & 2005 & 0.0708 & 0.2566 & 0 & 1 \\
\hline VGREWCOUNTRY & 2005 & 0.1322 & 0.3388 & 0 & 1 \\
\hline VGREWMISS & 2005 & 0.6993 & 0.4587 & 0 & 1 \\
\hline \multicolumn{6}{|l|}{ Mother } \\
\hline MAGE & 2078 & 50.6391 & 6.3759 & 35 & 75 \\
\hline MEDUC & 2044 & 11.6485 & 2.2250 & 7 & 18 \\
\hline MMARRIED & 2078 & 0.7897 & 0.4076 & 0 & 1 \\
\hline MPUBSEC & 2024 & 0.3014 & 0.4590 & 0 & 1 \\
\hline MlogHHINC & 1964 & 7.9654 & 0.5249 & 5.9915 & 10.6612 \\
\hline MGREWLCITY & 2078 & 0.0592 & 0.2360 & 0 & 1 \\
\hline MGREWMCITY & 2078 & 0.0423 & 0.2014 & 0 & 1 \\
\hline MGREWSCITY & 2078 & 0.0630 & 0.2431 & 0 & 1 \\
\hline MGREWCOUNTRY & 2078 & 0.1242 & 0.3298 & 0 & 1 \\
\hline MGREWMISS & 2078 & 0.7113 & 0.4533 & 0 & 1 \\
\hline 2001 & 2836 & 0.0709 & 0.2567 & 0 & 1 \\
\hline 2002 & 2836 & 0.0832 & 0.2763 & 0 & 1 \\
\hline 2003 & 2836 & 0.0649 & 0.2464 & 0 & 1 \\
\hline 2004 & 2836 & 0.0829 & 0.2757 & 0 & 1 \\
\hline 2005 & 2836 & 0.0705 & 0.2561 & 0 & 1 \\
\hline 2006 & 2836 & 0.0642 & 0.2451 & 0 & 1 \\
\hline 2007 & 2836 & 0.0815 & 0.2736 & 0 & 1 \\
\hline 2008 & 2836 & 0.0892 & 0.2851 & 0 & 1 \\
\hline 2009 & 2836 & 0.3928 & 0.4885 & 0 & 1 \\
\hline
\end{tabular}




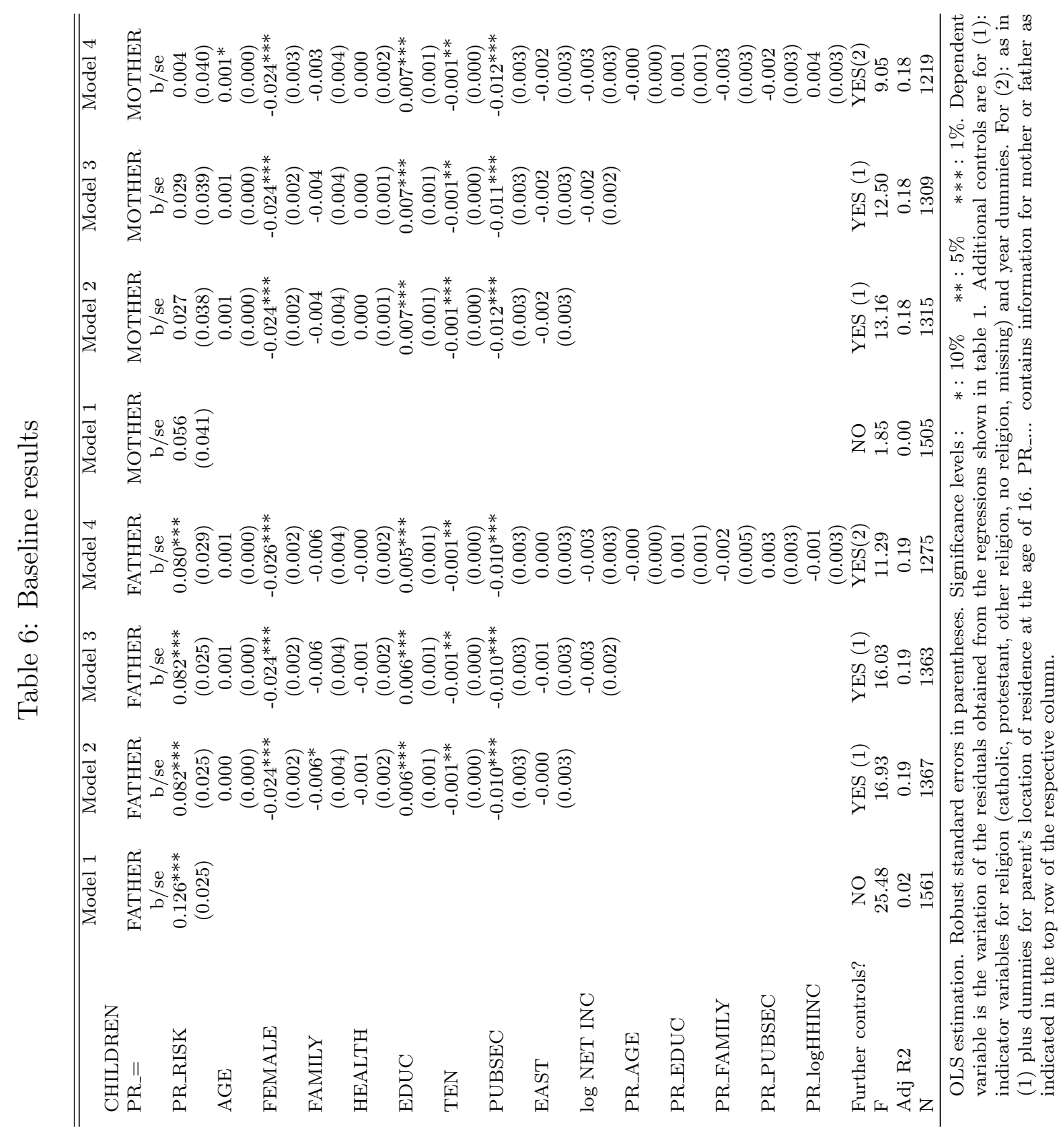



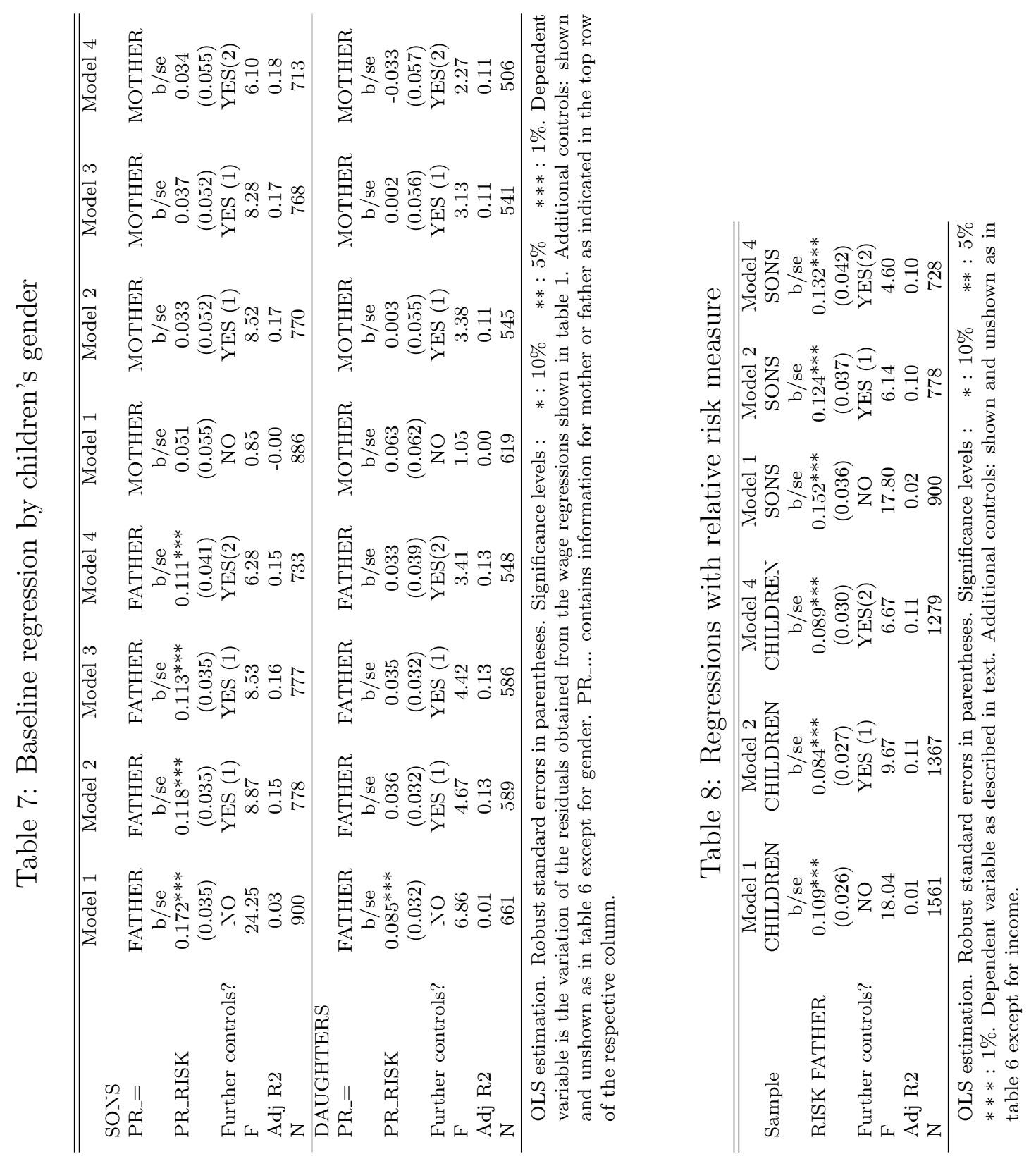
Table 9: Descriptive statistics - Mincer residuals

\begin{tabular}{|c|c|c|c|c|c|c|}
\hline & Obs & Num. of Cat. & mean & sd & $\min$ & $\max$ \\
\hline \multicolumn{7}{|c|}{ Baseline Mincer residual } \\
\hline Male & 67563 & 85 & 0.2909 & 0.0641 & 0.1879 & 0.4688 \\
\hline Female & 31882 & 62 & 0.2718 & 0.0448 & 0.2177 & 0.4191 \\
\hline \multicolumn{7}{|c|}{ Relative nature of income risk } \\
\hline Male & 67563 & 85 & 0.0392 & 0.0077 & 0.0241 & 0.0598 \\
\hline Female & 31882 & 62 & 0.0382 & 0.0057 & 0.0304 & 0.0556 \\
\hline \multicolumn{7}{|c|}{ Public versus Private Sector } \\
\hline Male Public & 13468 & 39 & 0.2575 & 0.0578 & 0.1745 & 0.4589 \\
\hline Female Public & 11070 & 28 & 0.2528 & 0.0499 & 0.1986 & 0.3965 \\
\hline Male Private & 51900 & 66 & 0.2961 & 0.0665 & 0.2099 & 0.4749 \\
\hline Female Private & 19462 & 50 & 0.2691 & 0.0395 & 0.1983 & 0.3895 \\
\hline \multicolumn{7}{|c|}{ Including ability - grades } \\
\hline Male & 14974 & 47 & 0.3007 & 0.0707 & 0.1807 & 0.5196 \\
\hline Female & 6231 & 23 & 0.2714 & 0.0497 & 0.1983 & 0.4355 \\
\hline \multicolumn{7}{|c|}{ Ability - comparable sample } \\
\hline Male & 14974 & 47 & 0.3008 & 0.0707 & 0.1836 & 0.5218 \\
\hline Female & 6231 & 23 & 0.2714 & 0.0497 & 0.1984 & 0.4355 \\
\hline \multicolumn{7}{|c|}{ West Germans only } \\
\hline Male & 51330 & 75 & 0.2812 & 0.0673 & 0.1686 & 0.4788 \\
\hline Female & 20490 & 51 & 0.2644 & 0.0443 & 0.2032 & 0.4097 \\
\hline \multicolumn{7}{|c|}{ Restriction of sample to 1991-1999 } \\
\hline Male & 27606 & 61 & 0.2686 & 0.0608 & 0.1859 & 0.4625 \\
\hline Female & 11963 & 35 & 0.2460 & 0.0437 & 0.1952 & 0.4281 \\
\hline \multicolumn{7}{|c|}{ Restriction of sample to $2000-2009$} \\
\hline Male & 37043 & 65 & 0.2883 & 0.06511 & 0.18120 & 0.4707 \\
\hline Female & 16889 & 45 & 0.2738 & 0.0432 & 0.2145 & .3982 \\
\hline
\end{tabular}



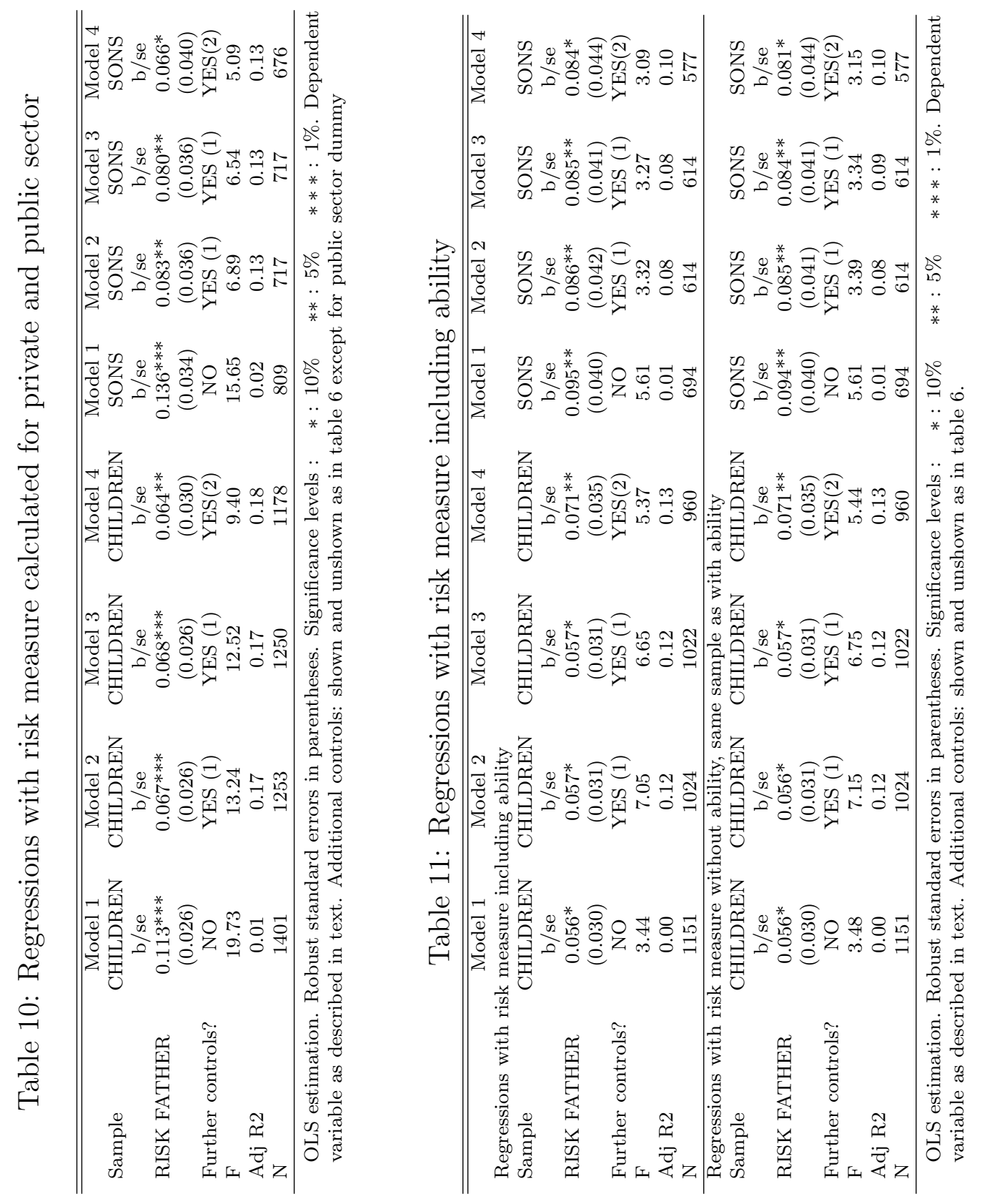

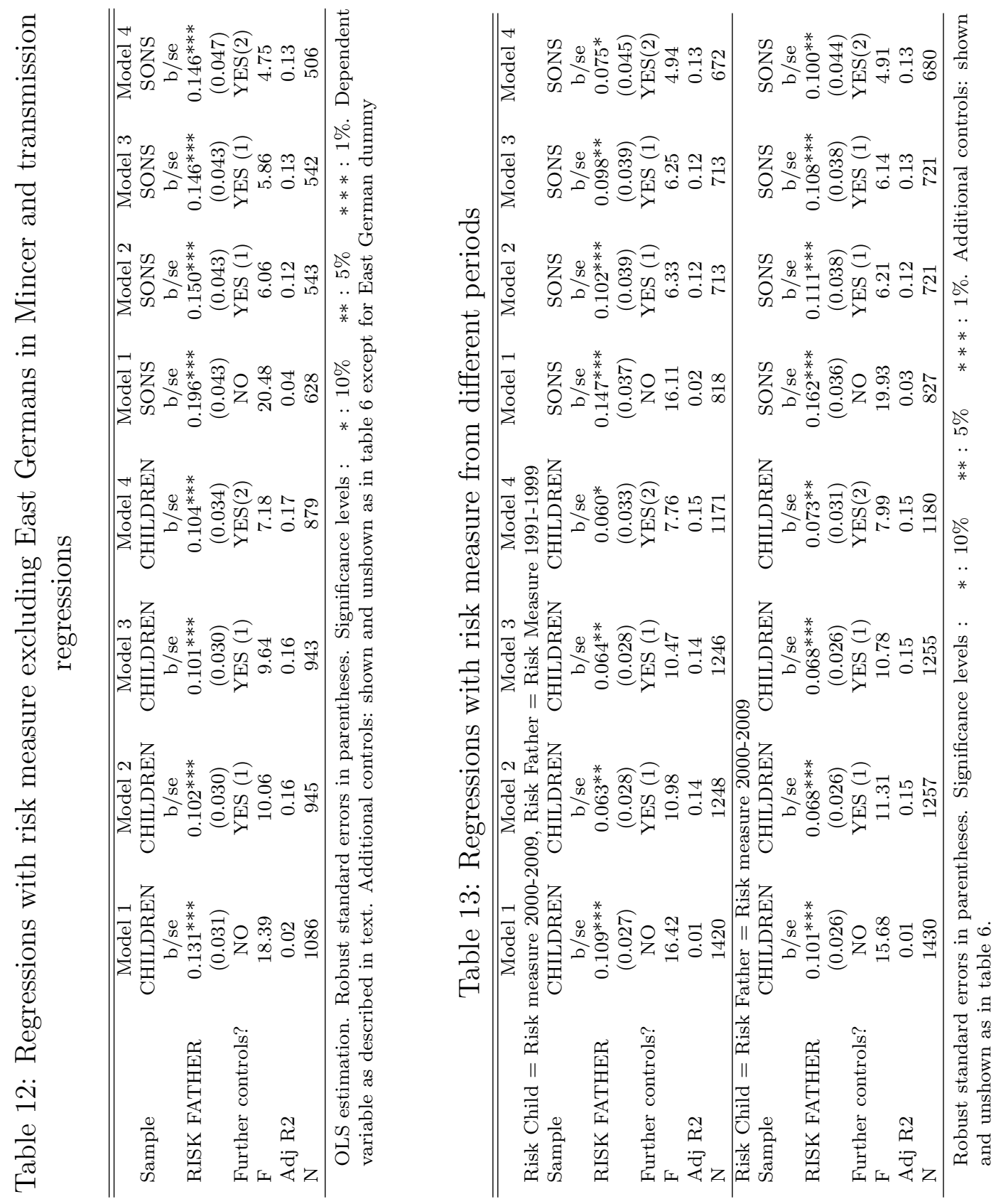

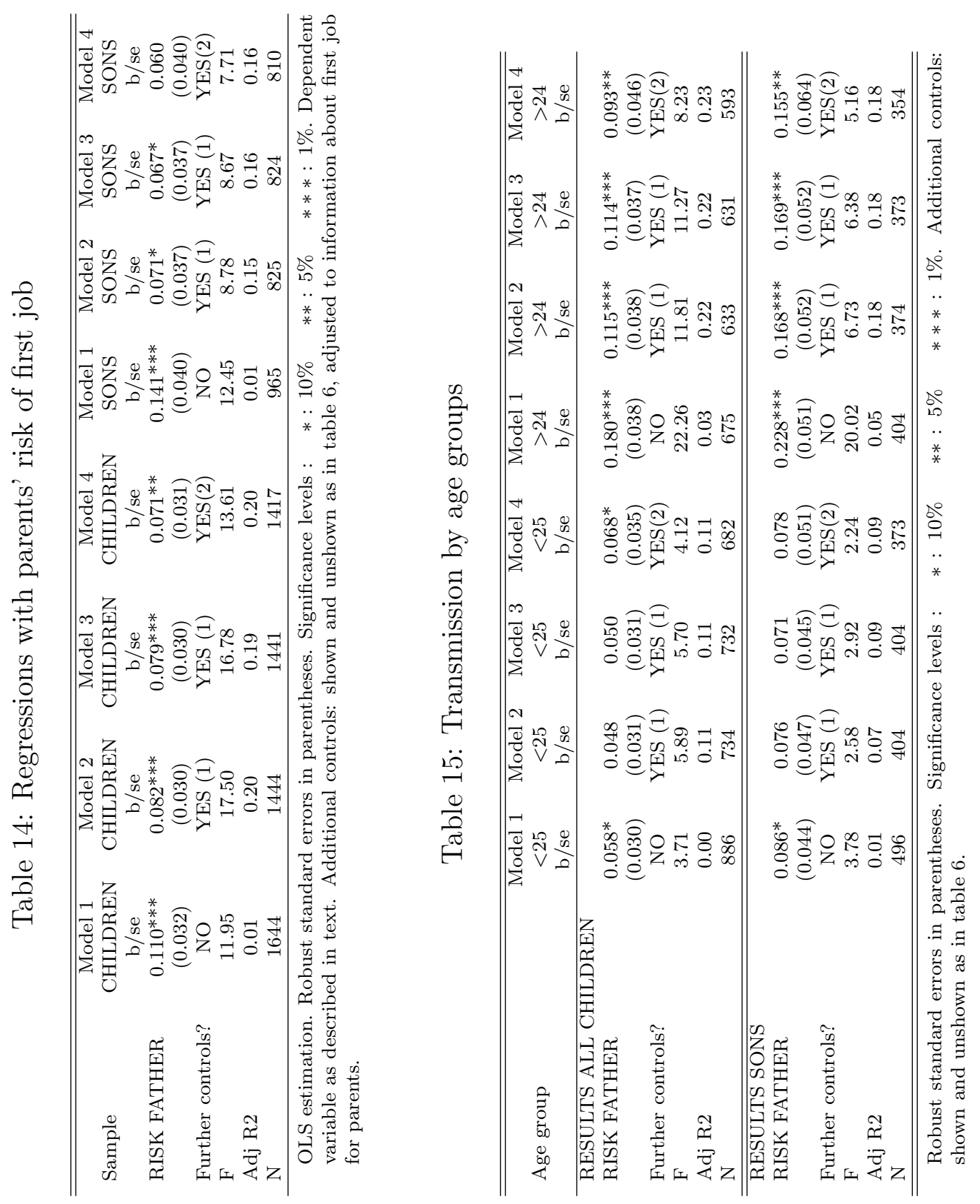